\title{
2
}

\section{'WE ARE NOT ALLOWED'}

\section{Barriers to Rohingya refugees' educational and economic opportunities}

\author{
Silvia Guglielmi, Jennifer Seager, Khadija Mitu, Jared \\ Kalow, Sarah Baird and Nicola Jones
}

\section{Introduction}

Young people are critical to the success of the 2030 Agenda for Sustainable Development (Sheehan et al., 2017; Ki-moon, 2016) and the promise of the Global Compact on Refugees. Adolescence (the age between 10 and 19 years) is a time of dynamic growth of an individual's cognitive, physical, social and emotional capabilities. However, a lack of coordinated attention to the world's 1.8 billion adolescents and youth could jeopardise global progress towards the Sustainable Development Goals (SDGs). In particular, investing in education and economic empowerment of adolescents has the promise of not only improving future outcomes for adolescents and their families but also supporting broader poverty reduction and development milestones (United Nations Department of Economic and Social Affairs (UN DESA), 2018; Kleinert and Horton, 2016; United States Agency for International Development (USAID), 2016; United Nations Population Fund (UNFPA), 2010).

Wedged between statelessness and a lack of official refugee status, displaced Rohingya girls and boys are particularly vulnerable to being left out of SDG targets for education and economic empowerment. From August 2017, the largest wave of Rohingya crossed the border into Bangladesh, ${ }^{1}$ fleeing crimes that the UN Special Rapporteur has claimed 'bear the hallmarks of genocide' (Office of the United Nations High Commissioner for Human Rights (OHCHR), 2018). Approximately 825,000 Rohingya refugees ${ }^{2}$ now live in 32 makeshift camps $^{3}$ in the Ukhia and Teknaf upazilas (sub-administrative units) of Cox's Bazar district - one of Bangladesh's poorest regions (United Nations High Commissioner for Refugees (UNHCR), 2020; Milton et al., 2017) - and remain entirely reliant on humanitarian assistance. Adolescents comprise almost a quarter (23 per cent) of the Rohingya in Bangladesh, ${ }^{4}$ and the multidimensional vulnerabilities they face make this a large-scale complex crisis with no easy answers. Three years on, there remains 
no long-term solution for stateless Rohingya refugees, and adolescents are being denied both formal schooling and employment opportunities.

This chapter draws on mixed-methods baseline data collected in 2019 as part of the Gender and Adolescence: Global Evidence (GAGE) programme to understand how Rohingya adolescents access education and economic opportunities. Drawing on quantitative and qualitative data from younger (10-14) and older (15-18) cohorts, our research captures the voices of Rohingya adolescents, including the structural and socio-cultural constraints they face.

\section{Context}

The Rohingya are among the most persecuted populations in the world and have faced displacement from Myanmar over several generations. The most recent influx into Bangladesh dwarfed previous outflows, with 711,364 Rohingya escaping systematic discrimination and human rights violations in Myanmar (Human Rights Council, 2018; Inter Sector Coordination Group (ISCG), 2017). Two of Cox's Bazar's upazilas, Ukhia and Teknaf, now have populations comprised of 76 per cent and 29 per cent refugees respectively (ACAPS, 2018). Cox's Bazar is among the lowest-performing of Bangladesh's districts for educational access, retention and performance, and its school completion rate is 26 per cent lower than the national rate (Education Cannot Wait, 2018). Notwithstanding significant improvements in recent decades, most residents in Cox's Bazar remain illiterate (Lemma et al., 2018). Alongside education deficits, 33 per cent of people in the district live below the poverty line, and 17 per cent live below the extreme poverty line (ibid.). The 2020 Joint Response Plan for the Rohingya reports that 1.3 million people - comprising both refugees and host community residents - are now in need of humanitarian assistance (ISCG et al., 2020).

Although the United Nations Convention on the Rights of the Child (UNCRC) mandates the sacrosanct right to education (UN General Assembly, 1989) and the Global Compact on Refugees calls for the progressive inclusion of refugees into host community schools and employment sectors (UNHCR, 2018), Rohingya adolescents have been denied these basic rights, partially due to their precarious legal status. Bangladesh is not a signatory to the 1951 Refugee Convention nor its 1967 Protocol, nor the 1954 and 1961 Statelessness Conventions (UNHCR, 2011), and it does not consider the Rohingya as refugees, placing them in a 'legal and humanitarian limbo' (Bhatia et al., 2018). Moreover, the limited capacity and political will of local districts to absorb the Rohingya into national education systems and employment have limited the scope for refugee inclusion in existing host community structures.

The implications of an absence of an internationally binding refugee policy in Bangladesh can be seen clearly in education, where Rohingya children can only access non-formal education in learning centres predominately run by United Nations agencies or non-governmental organisations (NGOs) (Magee et al., 2020; Reidy, 2020). Having set up functional infrastructure to accommodate educational 
provision, aid agencies encountered a series of political hurdles (Dryden-Peterson, 2017). In the camps, schools are called 'temporary learning centres', teachers are called 'volunteers' and the language of instruction is Burmese or English - all to stress the informality and temporary nature of the education on offer (ibid.). In fact, tripartite agreements between humanitarian actors, the Government of Bangladesh and the Government of Myanmar have culminated in an agenda geared towards voluntary repatriation of the Rohingya to Myanmar (ISCG et al., 2020; UNHCR, 2019) as the only durable solution. ${ }^{5}$

For older adolescents (15 years or older), learning centre education is not available and alternative training opportunities are scarce. ${ }^{6}$ The 2020 Joint Response Plan for the Rohingya crisis warns that 'an alarming 83 percent of the [Rohingya] adolescents and youth aged 15-24 years old don't have access to any educational or skills development activities' (ISCG et al., 2020: 70). Although not following any set curriculum (Olney et al., 2019), NGOs have set up classes and home-based learning for adolescents to provide skills training such as sewing, tailoring and cleaning, which can help them find a means for income in the camps, although uptake remains low. Ultimately, non-formal learning centre education and skills-based training are meant to equip Rohingya adolescents with life skills, positive health messaging and work opportunities with NGOs operating in the camps, but they are not intended to provide transferable skills for work outside, thus reinforcing the reality that the Rohingya essentially cannot leave their settlements (Bakali and Wasty, 2020). Research within the camps suggests that better integration of these fragmented informal education networks within NGO and government initiatives can fuel better outcomes and be more responsive to Rohingya needs (Olney et al., 2019).

The 2020 Joint Response Plan for the Rohingya crisis addresses the learning and training crisis, aiming to '[e]xpand and strengthen immediate access to equitable learning opportunities, in a safe and protective environment, for affected Rohingya refugee and host community girls and boys aged 3-24 years old' (ISCG et al., 2020: 70). The recent decision to allow younger adolescents in the camps in Grades 6-9 to access the formal Myanmar curriculum (although only a pilot initially) brings a welcome change to education refugee policy in Bangladesh. ${ }^{7}$

However, opening up formal education is only the first barrier to break down. In previous Rohingya refugee waves - after being denied education for five years - the Bangladesh government opened up access to formal education, granting use of its curriculum for primary students through UN support (Stavropoulou et al.,2017) and provided adolescent and adult learning courses. However, figures from 2002 show that enrolment for adolescents remained low (27 per cent for girls, 24 per cent for boys) (Médecins Sans Frontières-Holland (MSF) (2002), suggesting that significant hurdles remained, especially for students who had been excluded from education for some time. In addition to educational constraints, a lack of legislation designed to protect refugee livelihoods and grant them the right to work severely curtails their employment prospects (Akhter and Kusakabe, 2014; Zetter and Ruaudel, 2016).

Significant data gaps - particularly a lack of age- and gender-disaggregated data - exacerbate the challenges facing the Rohingya population. Due to their 
longstanding history of exclusion, the Rohingya are not included in national household surveys (Institute on Statelessness and Inclusion (ISI), 2014). There is a lack of evidence on intersecting dimensions, including structural and cultural constraints that hamper Rohingya adolescents' development. Moreover, there is insufficient understanding of what works to support adolescents living through a confined, protracted crisis. Those responding to the crisis need to understand the specific vulnerabilities facing Rohingya adolescents as well as their aspirations.

\section{Conceptual framing}

We take a capabilities approach as developed by Sen $(1984,2004)$, focusing on education and economic capabilities as critical arenas of development for adolescents, both in terms of their capacity to engage critically with their communities and in terms of future trajectories of employment, earnings and broader wellbeing. Higher educational attainment has been shown to be associated with higher income trajectories in both high- and low-income settings (Willis, 1986; Ashenfelter et al., 1999; Behrman et al., 2017). Further, educational access and economic empowerment have positive implications not only for the current generation but for future generations too, through intergenerational transmission (Aguero and Ramachandran, 2020).

Rohingya adolescents face both structural and cultural constraints to accessing education and economic opportunities that prevent them developing these capability sets. Structurally, the Bangladesh government's refusal to recognise the Rohingya as refugees and the lack of integration into local communities restricts access to education and economic markets. Moreover, cultural constraints faced by Rohingya adolescents affect girls and boys differently and need to be fully understood if adolescents are to receive adequate support to utilise their full set of competences. Due to conservative religious norms, Rohingya girls experience severe mobility restrictions from the onset of puberty (Bakali and Wasty, 2020; Olney et al., 2019; Ripoll, 2017), which result in lower educational access than boys (Bakali and Wasty, 2020; Cox's Bazar Education Sector, 2018, 2019). The religious tradition of purdah ('curtain' or 'veil') documented in various townships in Myanmar and maintained by displaced Rohingya dictates that upon reaching puberty, girls must stay within their family home until they marry (staying indoors often remains a feature of their married life too) (Ripoll, 2017; Oxfam International, 2018; Tay et al., 2018; Wake et al., 2019). Different gendered norms impact older adolescent boys, who are expected to earn income for their household (Akhter and Kusakabe, 2014), fuelling the progressive downscaling of their education.

\section{Methodology}

\section{Data collection and sample}

The findings reported here are based on mixed-methods data collected in Rohingya camps in Cox's Bazar, Bangladesh, as part of the GAGE longitudinal study. 
Quantitative data is nested within the Cox's Bazar Panel Survey (CBPS), which used a representative sample of 2,493 Rohingya refugee households, collected between April and August 2019.,9 Data collection took place across 32 of the 34 Rohingya camps. ${ }^{10}$ The GAGE representative sample comprises all 924 households within the CBPS sample with at least one adolescent aged 10-12 or 15-17 at the time of a household census. ${ }^{11}$ This study also includes GAGE data from an additional purposeful sample of 131 adolescents who were either married or were living with a disability from a subset of the camp locations, which was collected in September and October 2019. ${ }^{12}$ Although the purposeful sample also primarily targeted adolescents aged 10-12 and 15-17, some adolescents aged 13-14 and 18 were included based on purposeful sampling criteria. Overall, the GAGE sample includes 1,055 Rohingya adolescents living in refugee camps in Cox's Bazar. An overview of the quantitative sample is provided in Table 2.1 (panel A).

We also collected qualitative data from 73 adolescent girls and boys (purposely selected from the quantitative sample) in both age cohorts. The findings reported also stem from qualitative data gathered from interviews with 12 parents of Rohingya adolescents (6 mothers and 6 fathers) as well as 12 focus group discussions (FGDs) with girls and boys separately, and 6 FGDs with female and male community members separately, to better understand community perceptions and norms surrounding adolescence. Finally, we conducted in-depth semi-structured interviews with 9 key informants providing insights into field operations and ground presence vis-à-vis the Rohingya response. An overview of the qualitative fieldwork is provided in Table 2.1 (panel B).

Verbal consent and assent was obtained for all caregivers and adolescent respondents respectively. ${ }^{13}$ The GAGE research programme was approved by the George Washington University Committee on Human Research, Institutional Review Board (071721), the ODI Research Ethics Committee (02438) and the Human Subjects Committee for Innovations for Poverty Action IRB-USA (14742).

TABLE 2.1 Fieldwork in Rohingya camps, and research sample

\begin{tabular}{lrrr}
\hline & Female & Male & Total \\
\hline Panel A: Quantitative fieldwork & & & \\
Number of research sites & & & 32 \\
Adolescent interviews younger cohort (10-14) & 309 & 331 & 640 \\
Adolescent interviews older cohort (15-18) & 253 & 162 & 415 \\
Total & $\mathbf{5 6 2}$ & $\mathbf{4 9 3}$ & $\mathbf{1 , 0 5 5}$ \\
Panel B: Qualitative fieldwork & & & \\
Adolescent interviews younger cohort (10-12) & 16 & 18 & 34 \\
Adolescent interviews older cohort (15-18) & 26 & 13 & 39 \\
Parent interviews & 6 & 6 & 12 \\
Focus group discussions & 9 & 9 & 18 \\
Key informant interviews & 5 & 4 & 9 \\
Total & $\mathbf{6 2}$ & $\mathbf{5 0}$ & $\mathbf{1 1 2}$ \\
\hline
\end{tabular}




\section{Research sites}

Baseline fieldwork took place between April and October 2019 in 32 camps across Cox's Bazar district (25 in Ukhia and 7 in Teknaf). Qualitative fieldwork took place across three camps selected after a mapping exercise on humanitarian presence and

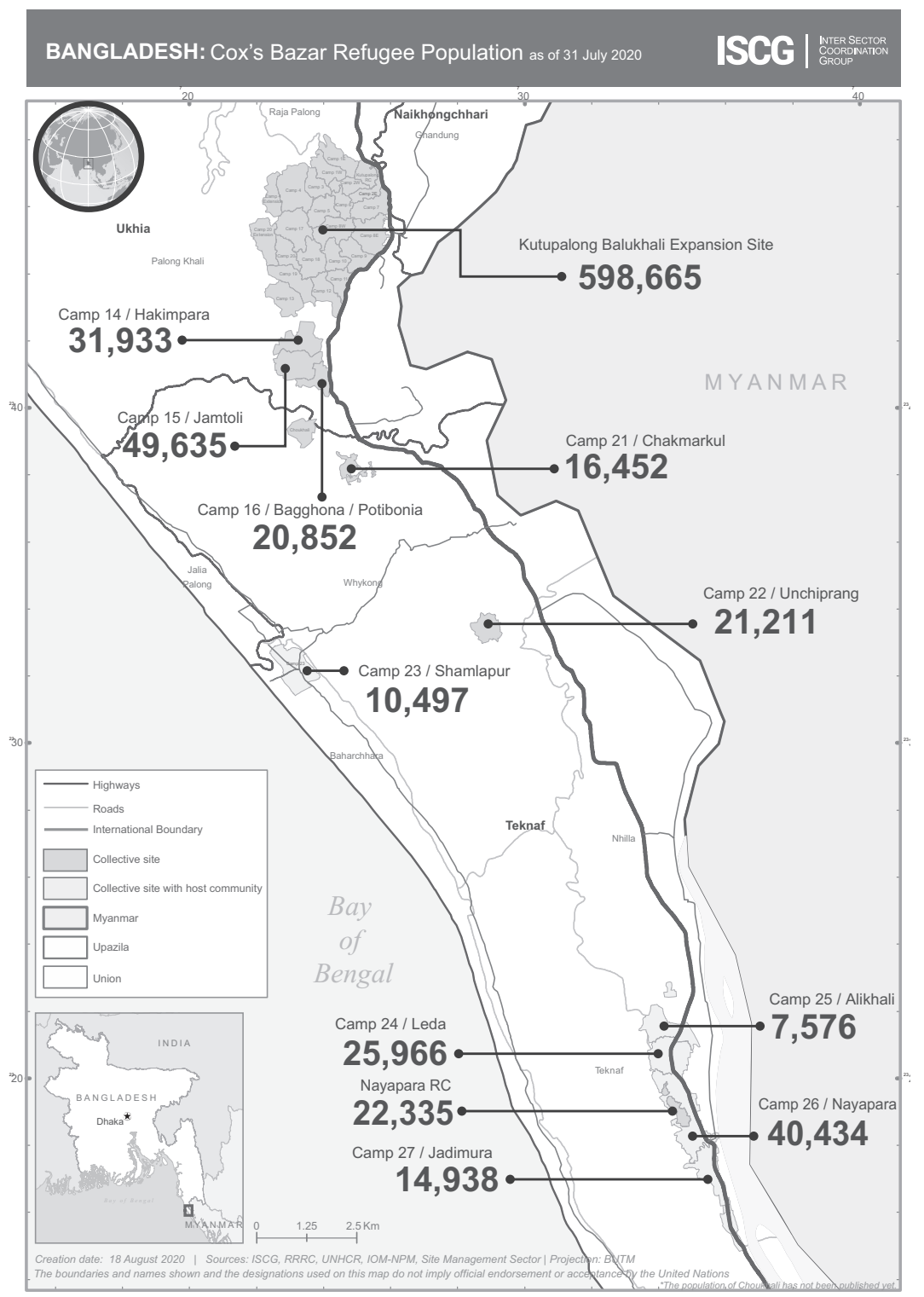

FIGURE 2.1 Map of Rohingya camps and population sizes.

Source: ISCG, RRRC, UNHCR, IOM-NPM, Site Management Sector (2020) 
population size. Drawing on ISCG metadata, we were able to map individual camp vulnerability by calculating the number of humanitarian partners implementing services, population size and the number of adolescent beneficiaries reached in each camp. We then selected a 'most vulnerable' site for adolescents (where there was a low ratio of beneficiaries being targeted), a 'middle-serviced' site and a 'bestserviced' site. To protect the privacy of study participants, the camp names will be anonymised in this and all other publications. Figure 2.1 shows the geographic distribution of the Rohingya camps in Cox's Bazar.

\section{Analysis}

To analyse the quantitative data, we construct a set of measures ${ }^{14}$ to capture the breadth of experience of Rohingya adolescents in relation to education and economic empowerment. We explore differences in means by gender and age, adjusting for sampling weights to make sure the estimates are representative of all adolescents living in the research locations. We also utilize regression analysis to test whether gender and age differences persist after controlling for household characteristics that may drive education and economic outcomes. ${ }^{15}$ Qualitative interview and FGD transcripts were initially translated from Chittagonian into Bangla and subsequently into English. Qualitative data were then coded following the GAGE codebook (Jones et al., 2018).

\section{Findings}

\section{Education}

Our results highlight the gender and age disparities that exist in Rohingya adolescents' educational trajectories. The quantitative findings presented in this section are based on mean comparisons between older and younger cohorts, boys and girls, as well as pairwise comparison between younger girls, older girls, younger boys and older boys.

\section{Educational enrolment}

Educational provision for Rohingya adolescents in camps is largely non-formal. ${ }^{16}$ On average, 49 per cent of adolescents in our sample are enrolled in non-formal schooling (panel A, column 2), including NGO-run programmes (70 per cent), Hafezi learning (which focuses on memorising the Qur'an in informal Islamic teaching spaces called maktabs and madrasas (14 per cent), private tutoring (12 per cent) and home-schooling or other forms of non-formal education (4 per cent). Table 2.2 (see Annex) presents summary statistics of our measures of educational access and attainment.

There is wide variation in enrolment by age and gender. Younger adolescents are 53 percentage points more likely to be enrolled in non-formal education than 
older adolescents (68 per cent compared to 15 per cent, panel A, columns 7 and 8). Qualitative data points to cultural norms as one reason why educational progression for older adolescents is limited, for both girls and boys - albeit for different reasons, as an international NGO staff member explained: '[The Rohingya community] do not recognise adolescents as children. In terms of boys they engage them in child labour and in terms of girls they face child marriage.' Across age cohorts, boys are 20 percentage points more likely to be enrolled in non-formal school than girls (58 per cent compared to 38 per cent, Table 2.2, columns 5 and 6) and gender disparity persists within age cohorts. Younger cohort boys are 16 percentage points more likely to be enrolled in school than younger girls (76 per cent compared to 60 per cent, panel B, columns 3 and 1). Among older cohort adolescents, boys are 26 percentage points more likely to be enrolled in non-formal schooling than girls (28 per cent compared to 2 per cent, panel B, columns 4 and 2 respectively).

Table 2.3 (see Annex) presents results of regression analysis estimating differences by age and gender, controlling for household characteristics that may drive enrolment. After controlling for these factors, regression estimates confirm that younger cohort boys are 48.4 percentage points more likely to be enrolled than older boys, and older girls are 24.3 percentage points less likely to be enrolled in non-formal schooling than older boys.

Among the younger cohort, enrolment in non-formal education is predominantly in NGO programmes (89 per cent of enrolled girls, 66 per cent of enrolled boys). Enrolment in Hafezi also comprises a large share of younger boys' enrolment in non-formal education (22 per cent among enrolled boys) and is the primary driver of higher enrolment of younger boys in non-formal education. Rohingya boys enrolled in Hafezi education attend classes every day, and while there is no set curriculum, the teaching style is very strict and focused. This contrasts with temporary learning centres, where the perception is that pupils do as they please and come and go as they wish. Islamic teachers, or Hujurs, are viewed as authoritarian figures that offer both support as well as firm (at times violent) instruction. A 15-year-old boy from camp A explained: 'If [students] study well, they don't batter them; otherwise they batter. They batter with a stick.'

For older boys, non-formal education predominantly consists of private tutoring (62 per cent) on traditional subjects, with some boys reporting enrolment in NGO programming (18 per cent) and Hafezi (17 per cent) learning. A majhi (Rohingya community leader) key informant explained that while Hafezi centres and maktabs are free in some camps, a 50 Bangladeshi taka (BDT) per month fee is collected from each household in other camps, regardless of whether children and adolescents attend classes. In addition, most Hafezi centres receive funding from Islamic organisations.

Very few older girls report enrolment in non-formal education $(n=8)$, and those who are enrolled engage in NGO programming, private tutoring and dropout education. Qualitative data underscored the severe mobility restrictions girls face upon reaching the age of 12 , typically coinciding with the onset of puberty, which leads them to drop out of education. ${ }^{17}$ A 16-year-old girl in camp A emphasised: 'Yes, 
I wished to study [but my] parents didn't allow me to go out. ... I was forced to be inside the home permanently.' Similarly, a participant in a young girls' FGD from camp B noted: 'My body will change in future. I have concern about it. I don't like it. Girls can't study at that time.'

Qualitative data suggests that the main driver of mobility restrictions on older girls is the religious norm, purdah, mandating that girls maintain family honour and decency by staying indoors. Respondents mentioned that family honour remains intact when girls are not seen by others - particularly men and boys - thus requiring them to remain homebound. An 11-year-old girl in camp C explained:

It's forbidden in our religion for older girls to go out. We aren't allowed to go anywhere. We are not allowed to go out of [our] home. People would see us! People would defame us, saying 'The girl is grown up and she goes out!' That's why we aren't allowed.

Adolescent girls' invisibility is thought to correlate with successful marriage prospects, which Rohingya families work hard to preserve even at the cost of education. A 16-year-old girl from camp A explained:

$[\mathrm{M}] \mathrm{y}$ father said, 'Our girl is grown up now. She doesn't need to go to school' and I stopped going. I wished to study [more] but my parents didn't allow me to go out.... Being confined at home means being grown up. We are confined at home ... and then we are to be married off. I was married off very early at the age of 14 .

Hujurs running Hafezi learning, and other religious leaders are believed to reinforce purdah and restrict the enrolment of older girls in education. An 18-year-old boy stated:

As adolescent girls age, they are prohibited from attending Hafezi classes. The girls who turn 12 years old [are] not allowed to go study. . . . [O]ur Hujur and Imam become upset [because] they are in the adolescent stage. They tell her ... that if [her] parents are educated they can read at home [or they can] bring a teacher to the home. Girls can read to a male teacher wearing a veil [but] they are not allowed to go out from home [and] they are not allowed to go to holy place because they are profane. If they go, adults will want to talk. How will she get married if she is seen with an unknown person? Our religious teachers say 'you are a daughter of a Muslim, won't you sin if [an] unknown person sees you? Your age is as same as a married girl!'

Qualitative data highlights that educational enrolment is also restricted for some adolescents with disabilities. Accessibility constraints in camps pose insurmountable hurdles for some adolescents who are unable to travel to school due to their physical and other impairments and are equally unable to afford private instruction. As an 18-year-old boy in Camp B explained, '[Tutors] don't come to my home. 
Who will come to my house to teach me? I don't have money. So, how can anyone teach me?' A recent vulnerability assessment (ACAPS, 2019) found that Rohingya individuals with physical and visual impairments face increased barriers in accessing services in the camps, primarily due to the hilly and uneven terrain. For adolescents with disabilities who either live in close proximity to learning centres or can rely on family chaperones to escort them, enrolment may increase, as explained by the mother of a ten-year-old girl living with a hearing disability in Camp B: 'She goes to Madrasa very early in the morning. After coming from madrasa she goes to school. The school is nearby and her brothers, relatives and the neighbours also go there. She comes and goes with them.'

\section{Educational attainment}

Educational attainment overall is low relative to age. While the youngest adolescents in our sample should have attained at least 6 years of education, average attainment is 3.7 years (Table 2.2). ${ }^{18}$ Previous literature reports that approximately half of the Rohingya children living in Cox's Bazar had not participated in any form of learning prior to arriving in Bangladesh (Education Cannot Wait, 2018) due to compounding factors including exclusion, while other estimates posit that over 80 per cent of the Rohingya are illiterate across age groups (Gallano, 2018). Our data matches this latter finding, with only 20 per cent of household heads in our sample being able to read. Further, the adjusted regression in column 2 of Table 2.3 shows that there is no statistically significant difference in years of education between older and younger adolescents, although there are between three and eight years of age difference between adolescents in the two cohorts. On average, boys have attained 1.5 more years of education than girls, and this gender difference increases as adolescents age (difference is one year in younger cohort and two years in older cohort). Older girls have attained the fewest years of education -1.9 years fewer than older boys (Table 2.3, column 2).

For adolescent boys, the costs of education as they age were mentioned as a reason for dropping out. A 17-year-old in camp C explained:

I used to study before [but] now I don't go to school because I can't bear the educational expenses. They take a lot of money, which I can't afford. [If the cost were paid] yes of course I would continue studying.

Preventing school dropout due to educational expenses is mitigated by incentivising schoolgoing, and our quantitative data shows that one-third of adolescents (mostly among the younger cohort) receive some education tuition or learning materials (Table 2.2, panel A, columns 7 and 8 and Table 2.3, column 4). Fifty per cent of younger adolescents receive some education benefits, while only 4 per cent of the older cohort do. Aside from tuition, learning materials provided vary, but include 'Eraser, school bag, pencil, cutter, books, notebooks . . . and snacks', explained a 12-year-old girl from camp A. 
We utilize regression analysis to explore the role of education benefits tuition or educational materials on participation in non-formal schooling. These results (Table 2.3, column 5) show that receiving education benefits is associated with a 36.6 percentage point increase in the likelihood of being enrolled in non-formal education programming, after controlling for age, gender and household characteristics. This indicates that providing educational support can foster enrolment.

\section{Educational aspirations}

Despite low educational attainment and access, the quantitative survey data suggests that Rohingya adolescents aspire to complete school through Grade 11 on average, with gender disparities in aspirations mirroring realities in attainment. Table 2.2 shows that girls aspire to two fewer years of education than boys (10.3 years vs. 12.2 years), with this disparity again persisting across age cohorts. It also persists after adjusting for household characteristics, with older girls having the lowest aspirations (2.3 years lower than older boys).

However, our qualitative data shows that many adolescents have also become resigned to their circumstances - discriminated against by displacement policy, poverty and/or norms limiting their educational access. A 16-year-old girl from camp C explained: 'We didn't have any chance to go to school there [in host communities]. We don't go out. What will I do?'The lack of educational options has profound repercussions for some older Rohingya adolescents, who lament the resulting loss of role models, as a 15-year-old boy from camp A reported: 'I don't have any aspiration because I couldn't study. If I studied, I would want to be like someone. But I didn't study. Whom do I want to be like?'

Qualitative data finds adolescents - boys primarily - aspiring to study in order to gain decent employment, including becoming doctors, teachers or Islamic theologians, as well as to support themselves and their families. A 17-year-old boy in camp A expressed this sentiment strongly:

I want to learn English. I can go to any place if I am educated. No one can stop my movement then. I will be respected by many people and I will get a job. If you study you can manage your own food, otherwise you have to depend on others.

Other adolescent boys and girls expressed their educational aspirations as linked to the intrinsic value of learning and bettering oneself. A 17-year-old boy in camp B highlighted this feeling: 'If any country takes any step for educating us, I [would] go abroad'; as did a 15-year-old girl in camp C: 'I have to study to talk beautifully like her [an NGO survey worker]. I have to treat others like the way she treated me. We have to show sympathy while we are talking to others and we have to study.' 


\section{Economic empowerment}

Our findings highlight that both structural and cultural constraints shape Rohingya adolescents' ability to pursue economic aspirations and to become economically empowered.

\section{Access to employment}

In terms of access to employment, Table 2.4 shows that 15 per cent of adolescents in our sample were engaged in paid work in the past 12 months (see Annex:Table 2.4, panel A, column 2). Work is concentrated among older boys, who are nearly 50 percentage points more likely to be working than any other group, and this holds true after adjusting for household characteristics (see Table 2.4, panel B, and Table 2.5, column 1). This is confirmed by an alternate set of questions that were asked only to the older cohort about employment in the past 12 months and past 7 days (see Table 2.4). Boys were 50 percentage points more likely to have been employed in the past 12 months than girls and 28 percentage points more likely to have been working in the past 7 days. Among those who were working, 46 per cent were their household's sole breadwinner (defined as being the only person working in the household).

Older adolescents were asked if they have been employed in the past 12 months and in the past 7 days (see Table 2.4, panel B, columns 3 and 4). While only 11 per cent of older girls had been employed in the 12 months preceding the survey, 61 per cent of older boys had been. Likewise, 6 per cent of older girls were employed in the 7 days preceding the survey compared to 34 per cent of older boys. These gender differences persist after controlling for key observables around household wealth (see Annex: Table 2.5, columns 1-3).

Older boys who were employed mostly did non-agricultural, unskilled manual labour. The most common jobs for older boys were reported as non-agricultural day labour (41 per cent) and groundwork (12 per cent) (digging and moving earth, possibly linked to structural site management). Older girls who worked were often tailors/seamstresses (58 per cent), as highlighted by a 16 -year-old married girl in camp A:

I sew dresses of others and I am paid. If I sew a set of three pieces, I am paid 100 taka for that. [But] I don't sew every day! During the time before Eid I earn much and in other times I earn less.

The second most common type of employment for older girls is as NGO volunteers (18 per cent). ${ }^{19}$

There is a perception among some adolescent boys that NGOs prioritise girls for employment in camps, as an 18-year-old boy from camp B commented: "[NGOs] want to give more jobs to the girls among the refugees. The girls get jobs in childfriendly spaces, even though their education qualification is low. However, our 
qualitative data underscores that there are not enough culturally appropriate job opportunities for older girls. While some girls would be eager to work to combat poverty and hunger, a 17-year-old girl in camp A explained that this option is not without consequences:

I can't eat properly. . . . If I can go out, I could do a job. I could sell several things at market. I can sell vegetables. I can sell sauces. But now I can't sell it. People will say a lot of things. 'That girl is going out of home', they will make fun of me.

Others seem committed to maintaining cultural norms, as an 18-year-old girl in camp B noted: 'But we work at home. Why should we work outside? ... Brothers work, fathers earn money. Why would I go for work?'

Securing work in the camps does not appear to be achievable for all adolescents, however, with some mentioning competition for camp jobs, patchy availability across locations or needing to fulfil criteria they cannot meet. A 17-year-old married girl in camp A said she wanted to work, but '[I have to] submit a CV and many other things ... to be a volunteer. How can I prepare that? No one helps me.' Others mentioned that direct connections with camp authorities facilitate the likelihood of getting a job, as a 17-year-old boy in camp A explained: 'I have to pay a bribe to get a job [but] I can't afford that. The authorities take the money. If we will give the money, we will get the job easily.' Quantitative findings mirror this, with most adults reporting getting a job through: a majhi or community leader (36 per cent); friends, neighbours or prior acquaintances (32 per cent); or being contacted by the employer (19 per cent). Networks seem to be critical in obtaining jobs - less than 5 per cent of adults reported getting a job through direct application.

While the Rohingya are not legally allowed to work in Bangladesh or to travel outside of camps, there is evidence that they do both (Kudrat-E-Khuda, 2020; Asylum Access, 2019; Reuters, 2018). However, it is not known how many adolescents work outside camps. A few adolescents mentioned going outside of camps to work, as a 17-year-old boy in camp C said: 'I work in a workshop in Teknaf. In a boat workshop. I am good at repairs.' In the quantitative data, reported commute times indicate that most adolescents engaged in paid labour do so predominantly inside the camps. Older working adolescents report a median commute time of ten minutes and over 75 per cent report walking to their jobs. Moreover, 62 per cent report working for NGOs, who typically conduct activities within camp grounds.

Very few adolescents in our sample (about 2 per cent) reported benefiting from any skills building or employment programme. Interestingly, programming targets girls primarily, even after adjusting for household characteristics (see Table 2.5, columns 4 and 5), although they are not engaging as much in paid labour. As a 15-year-old girl in camp A explained:

I go sew at 8 am and I am back home at 12 [noon] - they don't pay us, we are learning from them, that's why they don't pay us. We can earn money 
by teach[ing] others. I can earn money by sewing clothes if I have a sewing machine in my house. Other than that, I don't go anywhere. I always stay at home.

\section{Employment aspirations}

Our survey data reveals that when adolescents were asked about what type of job they aspire to, just over half (52 per cent) chose a professional career; 17 per cent said they aspired to work in skilled labour, while under 5 per cent said they aspired to work in unskilled labour. As adolescents age, they are less likely to aspire to professional careers, although it remains the most common aspiration: 38 per cent of older adolescents aspire to professional careers compared to 60 per cent of younger adolescents. The four most common career aspirations in our sample were teacher (33 per cent), tailor or seamstress (14 per cent), doctor (10 per cent) and religious officiant/leader ( 8 per cent). While boys and girls both aspire to be teachers, the other three occupations are largely gender-specific. Most girls aspire to be a teacher (29 per cent) or a tailor/seamstress ( 28 per cent). Boys aspire to be a teacher (35 per cent), religious officiant/leader (15 per cent) or a doctor (10 per cent).

Our qualitative data highlights that, for most adolescents, employment aspirations are focused primarily on earning money, and engaging in paid work appears to be a stand-alone aspiration. Securing an income is perceived as a way to purchase basic things for themselves and their families. Mitigating food insecurity and the ability to procure a greater variety and amount of food featured in qualitative interviews as correlated with employment aspirations and earning prospects. A 15-yearold girl in camp C explained:

With money I can buy something to eat, suppose [I could] open a shop for my mother, we can get some money and eat something from outside. This would be one kind of happiness.

That sentiment was echoed by a 15 -year-old boy from camp A, who stated: '[I want to earn a lot of money] so that I can eat properly'. The ability to cover health expenses was also mentioned in qualitative interviews, with a 15-year-old girl from camp A noting: 'I would spend my money for my father's treatment', as was the ability to purchase new clothes for themselves and their siblings. Our qualitative data underscores that adolescents aspire towards a degree of monetary self-reliance, as they continue to rely on humanitarian assistance to cover basic needs rather than purchasing them.

The prospect of earning money through employment is associated with peace of mind, particularly for older boys, who face strong expectations to provide for their families. A 19-year-old boy in camp B stated, 'I would feel peace when I have money, and an 18-year-old boy in camp A noted, 'My dream is in the future that I can earn money, I can maintain my family well, I can lead my life well. No one can abuse me.' Failing to meet these economic aspirations has led many adolescents 
to resort to negative coping mechanisms; selling items obtained through humanitarian organisations was frequently mentioned. An 18-year-old girl in camp A, for example, noted: 'We get some money by selling things that we got from NGOs'.

\section{Conclusion and recommendations}

Our research highlights the inadequacy of educational opportunities for Rohingya adolescents, the disconnect between the opportunities that are available and their aspirations and the significant challenges they face in ensuring a secure transition into adulthood. Most adolescents (especially older girls and boys) go through this critical developmental phase without a clear learning path, educational accreditation or skills progression, which not only has contemporaneous negative impacts but will likely negatively impact future generations (Willis, 1986; Ashenfelter et al., 1999; Behrman et al., 2017; Aguero and Ramachandran, 2020).

Disaggregating the data by age, gender, marital status and disability highlights that adolescents face different educational and economic constraints and opportunities at different stages of adolescence and on account of deeply entrenched gender norms. Our findings expand the knowledge base on the particular experiences of diverse individuals who, as adolescents, are often grouped together in studies with either children or adults.

Solutions for Rohingya adolescents in Cox's Bazar are more complex than providing educational opportunities in the camps. The historical and political context within which Rohingya adolescents' current and future lives are situated requires a bold and coordinated vision. Considering that agreements for safe and voluntary repatriation have yet to be secured and integration into the host country is not a viable option, policies and programmes should focus on guaranteeing a safe transition to adulthood for all Rohingya adolescents in the camps. As such, programming needs to prioritise sufficient decent work opportunities in camps so as to circumvent the need for bribery to obtain jobs, as is currently the case. The humanitarian operation in this protracted context might complement the focus on repatriation with an agenda geared towards refugee self-sufficiency in the interim. As they await their fate, supporting Rohingya adolescents to acquire gender-appropriate skills needed to work and earn a decent income in the camps will set the foundations for a pathway towards self-reliance and a future that is more in line with their aspirations.

To facilitate such an agenda, an analysis of skills-to-work transitions for adolescent girls and boys needs to be conducted in the design phase of skills-based interventions. Our research points to the positive role of educational support (such as providing tuition and materials) in expanding participation in educational programmes, suggesting that the expansion of analogous support within camps could increase access to skills programmes that operate there. Extending educational benefits to older boys so that they may learn new skills instead of fulfilling the cultural norm to earn an income for their families could also be piloted and assessed. Equally, it would be critical to investigate the role of educational benefits that are 
conditional on girls remaining in school and their impact on mobility restrictions and seclusion - and risks of child marriage. Moreover, urgent attention should be paid to the provision of mobile learning and chaperones to escort girls to training services, so that interventions reach adolescent girls undergoing puberty who are subject to the most severe mobility restrictions. Finally, a package of gendertransformative interventions around gendered social norms, targeting families and community leaders, should promote the importance of girls' education.

The transitory nature of education and employment provision in Cox's Bazar risks jeopardising the wellbeing of Rohingya adolescents in the short term but also the achievement of longer-term global goals and commitments enshrined in the Global Compact and the 2030 Agenda. Only when they can be assured of opportunities to access meaningful and inclusive learning trajectories and decent work opportunities will Rohingya adolescents be seen as potential contributors, rather than as a crisis to be tackled.

\section{Notes}

1 A total of 711,364 Rohingya fled Myanmar starting in August 2017 (UNHCR, 2020), 500,000 of whom arrived in the initial month alone (ISCG, 2017).

2 The Bangladesh government refers to the Rohingya as 'forcibly displaced Myanmar nationals', while the United Nations system refers to them as refugees (ISCG et al., 2020). In this chapter, this population is referred to as 'refugees'.

3 The Rohingya who arrived in 2017 joined other unregistered Rohingya who arrived in earlier waves of displacement. In addition, 35,000 registered Rohingya refugees from migration waves pre-2016 live in two registered refugee camps in the same area. We do not report findings on registered Rohingya in refugee camps.

4 Authors' own calculation based on the Joint Response Plan (2020) figures reporting that 23 per cent of Rohingya are in the 5-11 age bracket, 14 per cent are in the 12-17 age bracket and 41 per cent are in the 18-29 age bracket, and the assumption of equal distribution in each age band.

5 Integration into the host country and resettlement into a third country are options that have yet to gain coordinated buy-in from the multitude of partners that would require their implementation. As policy and programming actors pivotal to the Rohingya response appeal to meet humanitarian funding targets, which have escalated in response to needs since 2017 (OCHA, 2020) and donor fatigue sets in (Yuan Sun and Huang, 2019), ground realities show that adolescent Rohingya refugees are being sidelined and that they are at risk of becoming a lost generation (UNICEF, 2019; Ainul et al., 2018; Education Cannot Wait, 2018).

6 Children aged 4-14 receive non-formal learning via a tailor-made Learning Competency Framework curriculum developed by UNICEF and partners, delivered in more than 3,000 learning centres across the refugee camps (UNICEF, 2020).

7 While the piloting of a Myanmar curriculum in camps was scheduled for the spring of 2020 , its rollout has been indefinitely paused due to the Covid-19 pandemic and respective containment efforts.

8 The Cox's Bazar Panel Survey (CBPS) is a partnership between the Yale MacMillan Center Program on Refugees, Forced Displacement, and Humanitarian Responses, GAGE and the World Bank's Poverty and Equity Global Practice. Within the partnership, the Yale MacMillan team has a special interest in migration and employment history, the World Bank team has a special interest in consumption patterns and food security and the GAGE team has a special interest in issues affecting adolescents (see World Bank, 2019 and CBPS, 2019). 
9 The CBPS sample comprises a representative sample of 5,020 households across both camp (2,493 households) and host locations (2,527 households), within which 2,047 households had at least one adolescent who was included in the GAGE representative sample (924 camp adolescents and 1,124 host adolescents). See https://refugee.macmillan.yale.edu/research-outputs/coxs-bazar-panel-survey for additional information on the CBPS sample.

10 The sample excludes refugees living in Kutupalong Registered Camp and Nayapara Registered Camp who migrated prior to the 2017 migration waves. The vast majority (93 per cent) of the GAGE survey sample arrived in Bangladesh during 2017 or later.

11 It is possible that some of the adolescents may have had birthdays between the household census in January and February 2019 and the household survey that took place from March to July 2019, and were therefore 13 or 18 at the time of survey.

12 The purposeful sample adolescents come from camps 1E, A, 4, 9 and 12.

13 Surveys and interview questions were translated into Bangla and then delivered in the Chittagonian local dialect, which is mutually intelligible with the Rohingya language, and subsequently piloted. Quantitative and qualitative data were collected during faceto-face interviews by enumerators and interviewers who were trained extensively on translations from Bangla to Chittagonian, utilising pre-recorded translations for particularly difficult questions. For quantitative data collection, 86 per cent of girls and 72 per cent of boys were surveyed by enumerators of the same gender. For qualitative data collection, all adolescent girls and older boys were interviewed by researchers of the same gender as the adolescent, and the same is true for younger boys (except for five who were interviewed by female researchers). All enumerators and qualitative researchers were trained on working with young people (including child protection policies and ethical protocols) and on the GAGE research design and conceptual framework.

14 Our measures of educational enrolment and attainment include an indicator for being enrolled in non-formal school, highest grade attained and highest grade aspired to if there were no constraints. Non-formal education includes dropout education, homeschool, private tutoring, evening studies, summer and adult education programmes and $\mathrm{NGO}$-run programmes. Highest grade attained measures the number of years of education the adolescent completed in formal, government-sanctioned schooling; if the adolescent has never been enrolled in education, they are assigned a value of zero. Measures of economic empowerment include an indicator for whether the adolescent has done anything to get money or things for the household in the past 12 months. For older adolescents, we have two additional measures: indicators for working for remuneration in the past 7 days or in the past 12 months. Work for remuneration includes daily labour, working for wages or in-kind and self-employment activities, including agriculture. We also construct three indicators for the adolescent benefitting from a programme that provides: (1) education tuition or materials, (2) economic skills building and (3) employment. We examine all measures as outcomes, as well as analyse whether access to education tuition or materials impact education outcomes as a predictor.

15 For quantitative analysis, we present summary statistics of all outcomes and test for differences between four age and gender cohorts: younger cohort boys and girls (10-14 years) and older cohort boys and girls (15-18 years). We utilise regression analysis to understand whether age and gender differences persist after controlling for an asset index, literacy of household head, gender of household head, household size, month of survey interview and an indicator for being in the purposeful sample. The asset index, literacy of household head and gender of household head are proxies for household socioeconomic status and support for adolescent education, which has been found to be an important driver of educational achievement and aspirations (Black et al., 2005; White, 1982; Dalton et al., 2014; Genicot and Ray, 2017); moreover, adolescents in better-off households may be less likely to be engaged in paid work. Number of household members is included to adjust for the fact that larger families may have more assets, which we use to construct the asset index, as well as to control for larger households possibly choosing to allocate 
resources differently. We include sampling weights in calculating all means and in regression analysis so that our estimates are representative of the study area, as well as cluster standard errors by the sampling block within the camp.

16 In the quantitative data 4 per cent of adolescents report being enrolled in formal education.

17 Wider CBPS data has revealed that among secondary school-age Rohingya adolescents, '41 percent of boys cite that they don't have enough money, but for 51 percent of girls the main reason for not attending school is social restrictions' (World Bank, 2019: 7).

18 Fifty per cent of the sample reported highest grade attained in Myanmar, with the other 50 per cent reporting highest grade attained in Bangladesh.

19 Rohingya refugee volunteers are engaged in many roles, for differing amounts of time, with a diverse range of stipends. For the latest guidance on volunteer jobs and incentives, see: Office of the Refugee Relief Repatriation Commissioner in Cox's Bazar (RRRC) and ISCG (2018).

\section{References}

ACAPS. (2018) Rohingya crisis: host community review thematic report - January 2018. NPM ACAPS Analysis Hub. Available at: www.acaps.org/special-re-port/ rohingya-crisis-host-communities-review

ACAPS. (2019) Vulnerabilities in the Rohingya refugee camps. ACAPS Thematic Report. Available at: www.acaps.org/country/bangladesh/special- reports

Aguero, J. M., and Ramachandran, M. (2020) The intergenerational transmission of schooling among the education-rationed. Journal of Human Resources 55(2): 504-538.

Ainul, S., Ehsan, I., Haque, E. F., Amin, S., Rob, U., Melnikas, A. J., and Falcone, J. (2018) Marriage and sexual and reproductive health of Rohingya adolescents and youth in Bangladesh: a qualitative study. Dhaka, Bangladesh: Population Council.

Akhter, S., and Kusakabe, K. (2014) Gender-based violence among documented Rohingya refugees in Bangladesh. Indian Journal of Gender Studies 21(2): 225-246.

Ashenfelter, O., Colm, H., and Oosterbeek, H. (1999) A review of estimates of the schooling/earnings relationship, with tests for publication bias. Labour Economics 6(4): 453-470.

Asylum Access. (2019) Refugee work rights report: refugee access to fair and lawful work in Asia. Oakland, CA: Asylum Access. Available at: https://asylumaccess.org/wp-content/ uploads/2019/11/Asia-RWR_FINAL.pdf

Bakali, N., and Wasty, S. (2020) Identity, social mobility, and trauma: post-conflict educational realities for survivors of the Rohingya genocide. Religions 11(5): 241.

Behrman, J. R., Schott, W., Mani, S., Crookston, B. T., Dearden, K., Duc, L. T., Fernald, L. C. H., and Stein, A. D. (2017) Intergenerational transmission of poverty and inequality: parental resources and schooling attainment and children's human capital in Ethiopia, India, Peru, and Vietnam. Economic Development and Cultural Change 65(4): 657-697.

Bhatia, A., Mahmud, A., Fuller, A., Shin, R., Rahman, A., Shatil, T., Sultana, M., Morshed, K. A. M., Leaning, J., and Balsari, S. (2018) The Rohingya in Cox's Bazar: when the stateless seek refuge. Health and Human Rights Journal 20(2): 105-122.

Black, S. E., Devereux, P. J., and Salvanes, K. G. (2005) Why the apple doesn't fall far: understanding intergenerational transmission of human capital. American Economic Review 95(1): 437-449.

Cox's Bazar Education Sector. (2018) Joint education needs assessment: Rohingya refugee in Cox's Bazar, June 2018. Cox's Bazar: Cox's Bazar Education Sector. Available at: https://reliefweb.int/report/bangladesh/joint-education-needs-assessment-rohingyarefugee-cox-s-bazar-june-2018 
Cox's Bazar Education Sector. (2019) Education needs assessment: Rohingya refugee response, March 2019. Cox's Bazar: Cox's Bazar Education Sector.

Cox's Bazar Panel Survey. (2019) Cox's Bazar panel survey: fact sheet. New Haven, CT: Innovations for Poverty Action and Yale MacMillan Centre.

Dalton, P. S., Ghosal, S., and Mani, A. (2014) Poverty and aspirations failure. The Economic Journal 126(590): 165-188. https://doi.org/10.1111/ecoj.12210

Dryden-Peterson, S. (2017) Refugee education: education for an unknowable future. Curriculum Inquiry 47: 14-24.

Education Cannot Wait (ECW). (2018) Education for Rohingya refugees and host communities in Bangladesh: Education Cannot Wait facilitated multi-year resilience programme 2018-2020. Available at: www.unesco.org/new/fileadmin/MULTIMEDIA/FIELD/ Dhaka/pdf/EDU/ECW_MYRP_Bangladesh_2018.pdf

Gallano, H. R. (2018) Education capacity self-assessment: transforming the education humanitarian response of the Rohingya refugee crisis, Cox's Bazar. Education in Emergencies and UNICEF. Available at:https://reliefweb.int/report/bangladesh/education-capacity-self-assessmenttransforming-education-humanitarian-response

Genicot, G., and Ray, D. (2017) Aspirations and inequality. Econometrica 85(2): 489-519. https://doi.org/10.3982/ECTA13865

Human Rights Council. (2018) Thirty-ninth session A/HRC/39/64: human rights situations that require the Council's attention. Report of the independent international fact-finding mission on Myanmar. Available at: www.ohchr.org/EN/HRBodies/HRC/MyanmarFFM/ Pages/ReportoftheMyanmarFFM.aspx

Institute on Statelessness and Inclusion (ISI). (2014) The world's stateless. The Netherlands: Wolf Legal Publishers (WLP). Available at: www.institutesi.org/worldsstateless.pdf

Inter Sector Coordination Group (ISCG). (2017) Humanitarian response plan: Rohingya refugee crisis, September 2017 - February 2018. Available at: https://reliefweb.int/ report/bangladesh/bangladesh-humanitarian-response-plan-september-2017-february2018-rohingya

ISCG, RRRC, UNHCR, IOM-NPM, Site Management Sector. (2020) Bangladesh: Cox's Bazar refugee population as of 31 July 2020. Available at: www.humanitarianresponse. info/sites/www.humanitarianresponse.info/files/documents/files/20200818_cox_ bazar_reference_map_with_pop_id0225.pdf

Jones, N., Camfield, L., Coast, E., Samuels, F., Hamad, B. A., Yadete,W., Amayreh,W., Odeh, K. B., Sajdi,J., Rashid, S., Sultan, M., Małachowska,A., and Presler-Marshall, E. (2018) GAGE baseline qualitative research tools. London: Gender and Adolescence: Global Evidence.

Ki-Moon, B. (2016) Sustainability - engaging future generations now. The Lancet 387(10036): 2356-2358. DOI: 10.1016/S0140-6736(16)30271-9

Kleinert, S., and Horton, R. (2016) Adolescent health and wellbeing: a key to a sustainable future. The Lancet 387(10036): 2355-2356. DOI: 10.1016/S0140-6736(16)30297-5

Kudrat-E-Khuda, B., and Scott, M. W. (Reviewing editor). (2020) The impacts and challenges to host country Bangladesh due to sheltering the Rohingya refugees. Cogent Social Sciences 6(1): 1770943. https://doi.org/10.1080/23311886.2020.1770943

Lemma, A. F., Quattri, M., Hagen-Zanker, J., Wake, C., Raihan, S., and Eusuf, A. (2018) Strategies for inclusive growth in Cox's Bazar. Bangladesh Economic Dialogue on Inclusive Growth (EDIG) Research Reports No. 4. London: Overseas Development Institute and the Asia Foundation.

Magee, A., Diwakar,V., and Nicolai, S. (2020) Strengthening coordinated education planning and response in crises. London: Overseas Development Institute. Available at: www.odi.org/ sites/odi.org.uk/files/resource-documents/200428_bangladesh.pdf 
Médecins Sans Frontières-Holland (MSF). (2002) 10 years for the Rohingya refugees in Bangladesh: past, present and future. Paris: MSF.

Milton, A. H., Rahman, M., Hussain, S., Jindal, C., Choudhury, S., Akter, S., Ferdousi, S., Mouly, T. A., Hall, J., and Efird, J. T. (2017) Trapped in statelessness: Rohingya refugees in Bangladesh. International Journal of Environmental Research and Public Health 14(8): 942. DOI: $10.3390 /$ ijerph14080942

Office for the Coordination of Humanitarian Affairs (OCHA). (2020) Financial Tracking Service dashboard. Available at: https://fts.unocha.org/

Office of the Refugee Relief Repatriation Commissioner in Cox's Bazar (RRRC) and ISCG. (2018) Guidance on Rohingya volunteer incentive rates, April 2018. Available at: www.humanitarianresponse.info/en/operations/bangladesh/document/volunteerincentive-rates

Office of the United Nations High Commissioner for Human Rights (OHCHR). (2018) Statement by Ms Yanghee Lee, Special Rapporteur on the situation of human rights in Myanmar at the 37th session of the Human Rights Council. Available at: www.ohchr. org/EN/NewsEvents/Pages/DisplayNews.aspx?NewsID=22806\&LangID=E

Olney, J., Haque, N., and Mubarak, R. (2019) We must prevent a lost generation: community-led education in Rohingya camps. Oslo: Peace Research Institute Oslo (PRIO).

Oxfam International. (2018) One year on: time to put women and girls at the heart of the Rohingya response. Oxford, UK: Oxfam GB for Oxfam International.

Reidy, K. (2020) Expanding education for Rohingya refugee children in Bangladesh. UNICEF, 10 February. Available at: www.unicef.org/rosa/stories/expanding-educationrohingya-refugee-children-bangladesh

Reuters. (2018) Under the radar, Rohingya refugees make a living in Bangladesh. The World, 15 June. Available at: www.pri.org/stories/2018-06-15/under-radar-rohingya-refugeesmake-living-myanmar

Ripoll, S. (2017) Social and cultural factors shaping health and nutrition, wellbeing and protection of the Rohingya within a humanitarian context. Brighton, UK: Institute of Development Studies/UNICEF.

Sen, A. (1984) Commodities and capabilities. Oxford: Oxford University Press.

Sen, A. (2004) Capabilities, lists, and public reason: continuing the conversation. Feminist Economics 10(3): 77-80.

Sheehan, P., Sweeny, K., Rasmussen, B., Wils, A., Friedman, H. S., Mahon, J., Patton, G. C., Sawyer, S. M., Howard, E., Symons, J., Stenberg, K., Chalasani, S., Maharaj, N., Reavley, N., Shi, H., Fridman, M., Welsh, A., Nsofor, E., and Laski, L. (2017) Building the foundations for sustainable development: a case for global investment in the capabilities of adolescents. The Lancet 390(10104): 1792-1806. https://doi.org/10.1016/S0140-6736(17)30872-3.

Stavropoulou, M., Marcus, R., Rezel, E., Gupta-Archer, N., and Noland, C. (2017) Adolescent girls' capabilities in Bangladesh. London: Gender and Adolescence: Global Evidence.

Tay, A. K., Islam, R., Riley, A., Welton-Mitchell, C., Duchesne, B., Waters,V.,Varner, A., Silove, D., and Ventevogel, P. (2018) Culture, context and mental health of Rohingya refugees: a review for staff in mental health and psychosocial support programmes for Rohingya refugees. Geneva: UNHCR.

UNFPA. (2010) The case for investing in young people as part of a national poverty reduction strategy. New York: UNFPA. Available at: www.unfpa.org/publications/case-investingyoung-people

UNHCR. (2011) States of denial: a review of UNHCR's response to the protracted situation of stateless Rohingya refugees in Bangladesh. Geneva: UNHCR Policy Development and Evaluation Service. 
UNHCR. (2018) Report of the United Nations High Commissioner for Refugees, Part II Global compact on refugees. Geneva: UNHCR. Available at: www.unhcr.org/gcr/GCR_English. pdf

UNHCR. (2019) A solidarity approach for the people of Rakhine state: the way forward. Available at: http://institutions.northsouth.edu/rohingya-2019/wp-content/ uploads/2019/07/A-Solidarity-Approach-for-the-People-of-Rakhine-State-Mar19.pdf

UNHCR. (2020) Rohingya emergency. Available at: www.unhcr.org/rohingya-emergency. html

United Nations Children's Fund (UNICEF). (2019) Beyond survival, Rohingya refugee children in Bangladesh want to learn. Dhaka, Bangladesh: UNICEF.

United Nations Department of Economic and Social Affairs (UN DESA). (2018) World youth report: youth and the 2030 agenda for sustainable development. Available at: www. un.org/development/desa/youth/world-youth-report/wyr2018.html

United Nations General Assembly. (1989) Convention on the rights of the child. Available at: www.ohchr.org /en/professionalinterest/pages/crc.aspx

United Nations High Commissioner for Refugees (UNHCR). (2020a) Operations portal, Refugee response in Bangladesh. Available at: https://data2.unhcr.org/en/situations/ myanmar_refugees

United States Agency for International Development (USAID). (2016) U.S. global strategy to empower adolescent girls. Washington, DC: USAID.

Wake, C., Barbelet,V., and Skinner, M. (2019) Rohingya refugees' perspectives on their displacement in Bangladesh: Uncertain futures. London: Humanitarian Practice Group Working Paper/ Overseas Development Institute.

White, K. R. (1982) The relation between socioeconomic status and academic achievement. Psychological Bulletin 91(3): 461-481. https://doi.org/10.1037/0033-2909.91.3.461

Willis, R. J. (1986) Wage determinants: a survey and reinterpretation of human capital earnings functions. In: Card, D., and Ashengelter, O. (Eds.), Handbook of labor economics, Vol. 1. Amsterdam: North Holland, 525-602.https://doi.org/10.1016/S1573-4463(86)01013-1

World Bank. (2019) The Cox's Bazar Panel Survey: Baseline data on displaced Rohingya and their host population. CBPS Brief 1, Poverty and Equity GP. Washington, DC: United States: World Bank Group.

Yuan Sun, I., and Huang, C. (2019) Designing a medium-term response to the rohingya refugee crisis: ideas for Bangladesh, the International Community, and the Private Sector. Washington, DC: Center for Global Development. Available at: www.cgdev.org/publication/ designing-medium-term-response-rohingya-refugee-crisis-ideas-bangladesh

Zetter, R., and Ruaudel, H. (2016) Refugees' right to work and access to labor markets - an assessment. Part II: country cases (preliminary). Global Knowledge Partnership on Migration and Development (KNOMAD). Available at: www.knomad.org/publication/ refugees-right-work-and-access-labor-markets-assessment-country-case-studies-part-2 


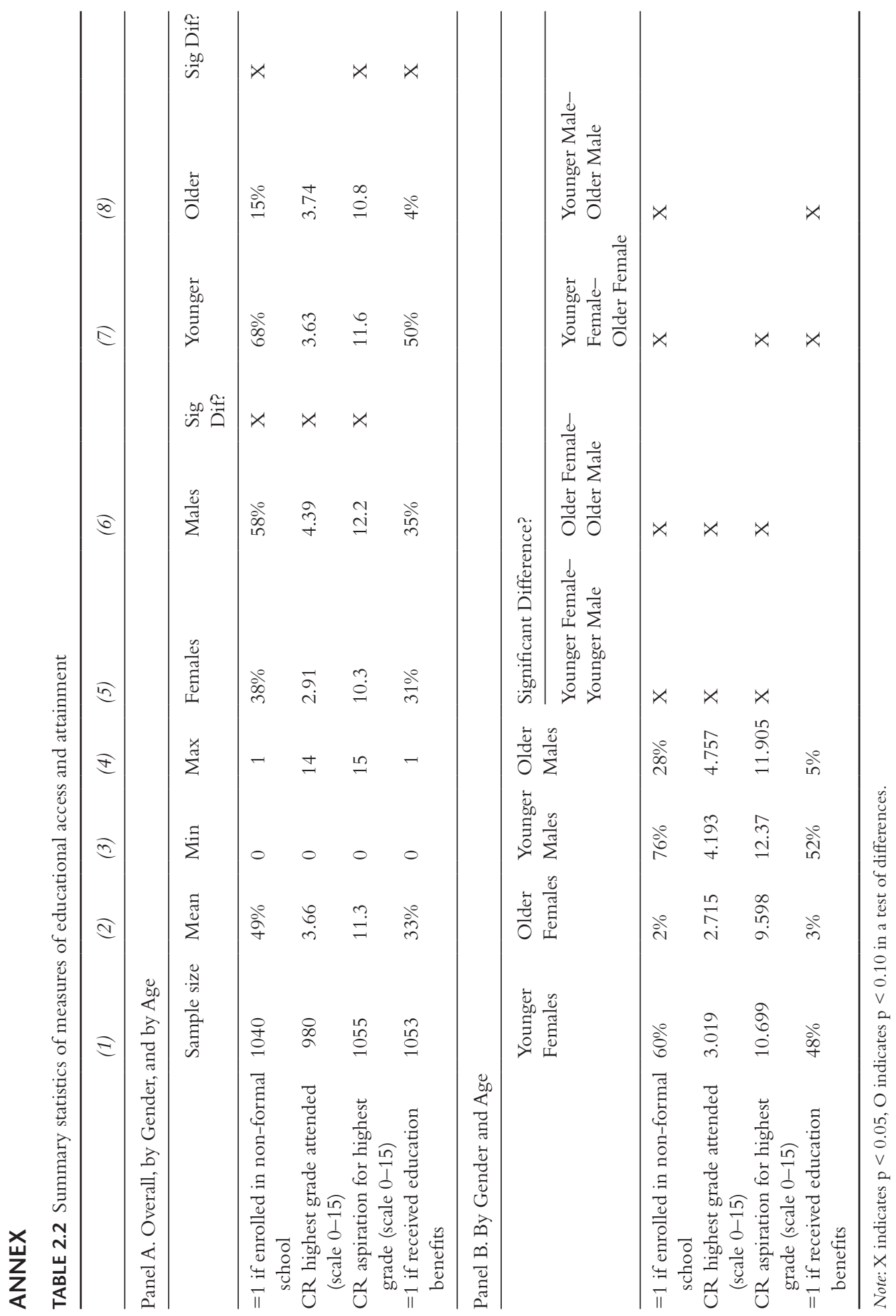


50 Silvia Guglielmi et al.

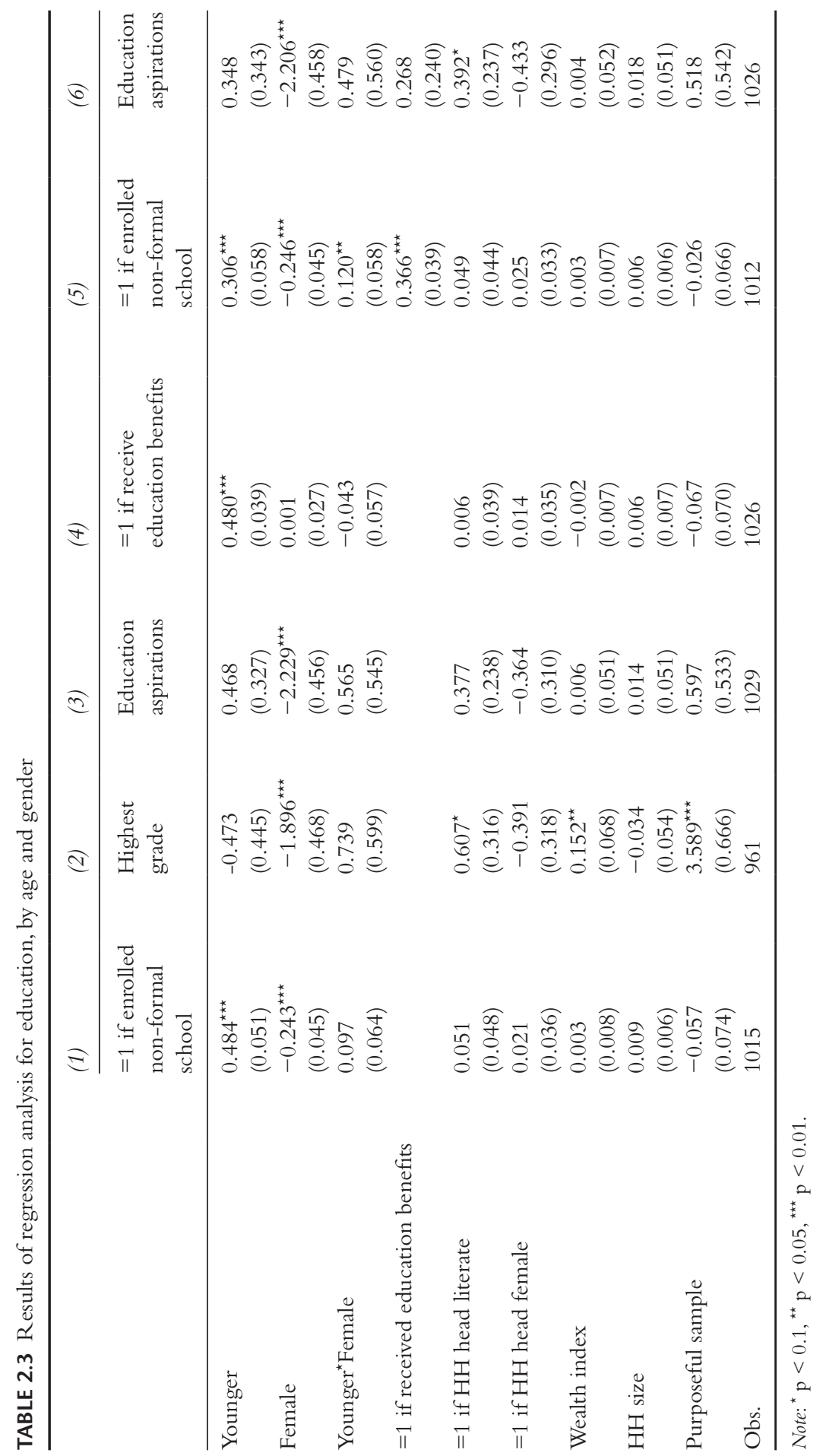




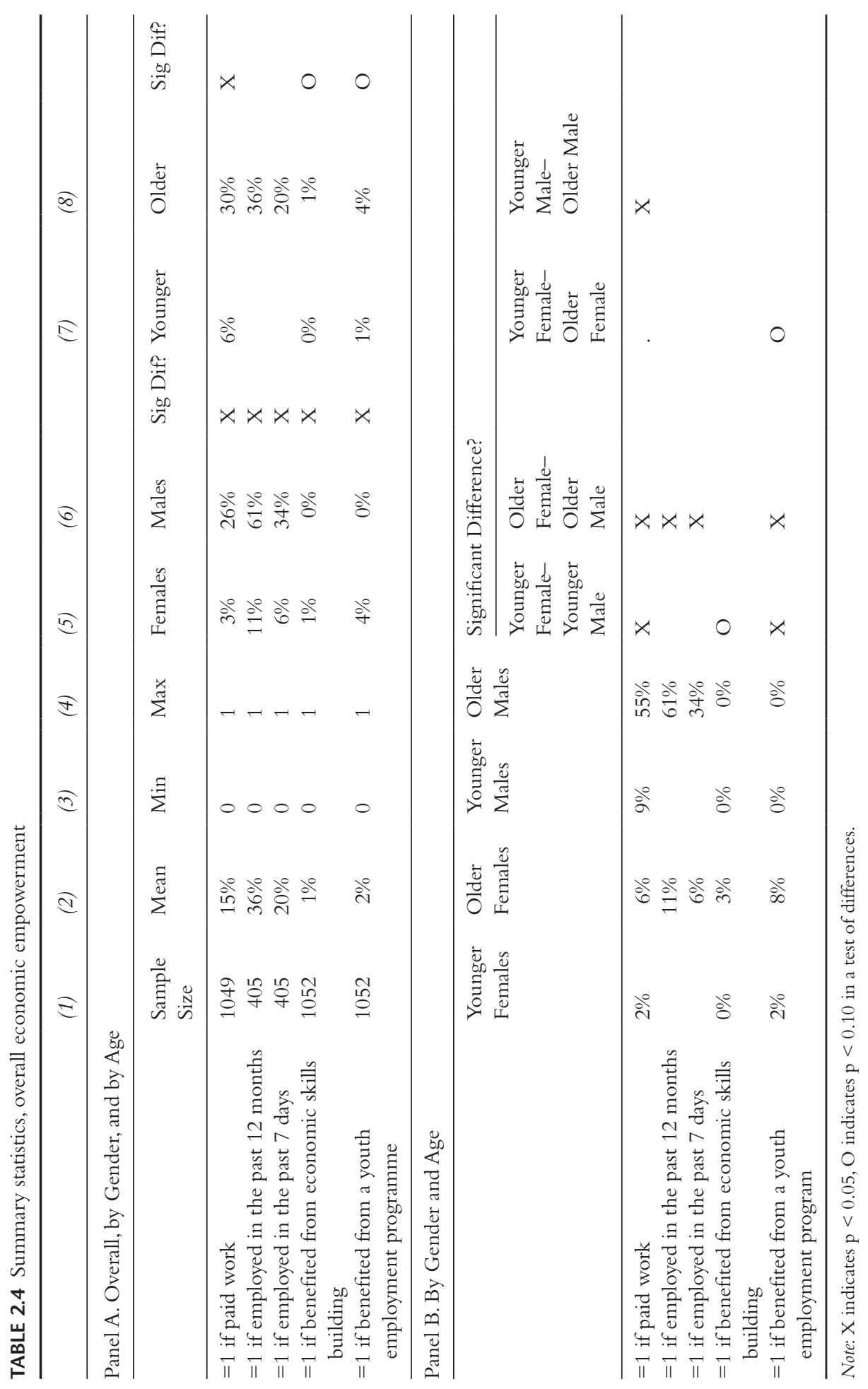


52 Silvia Guglielmi et al.

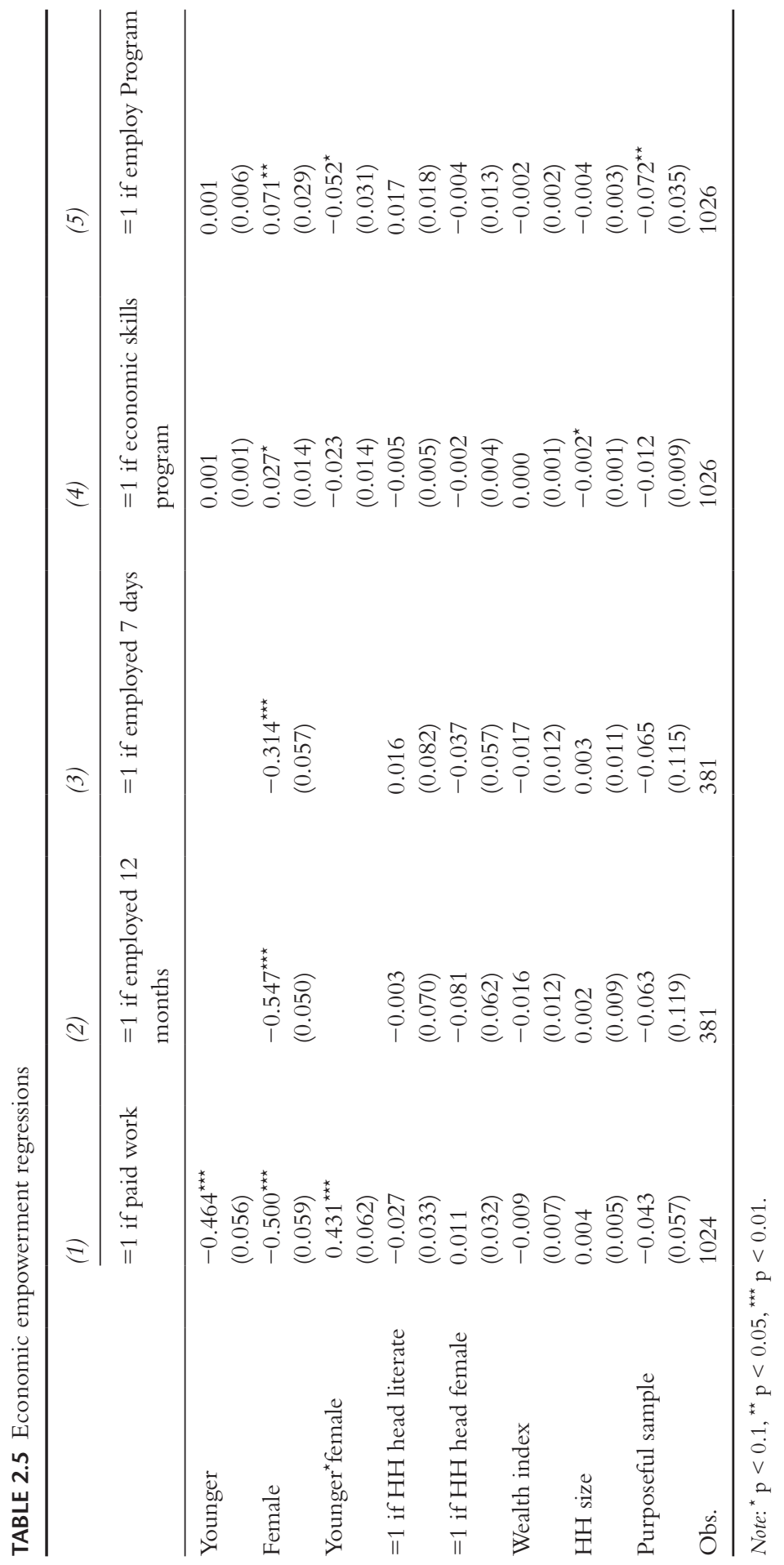




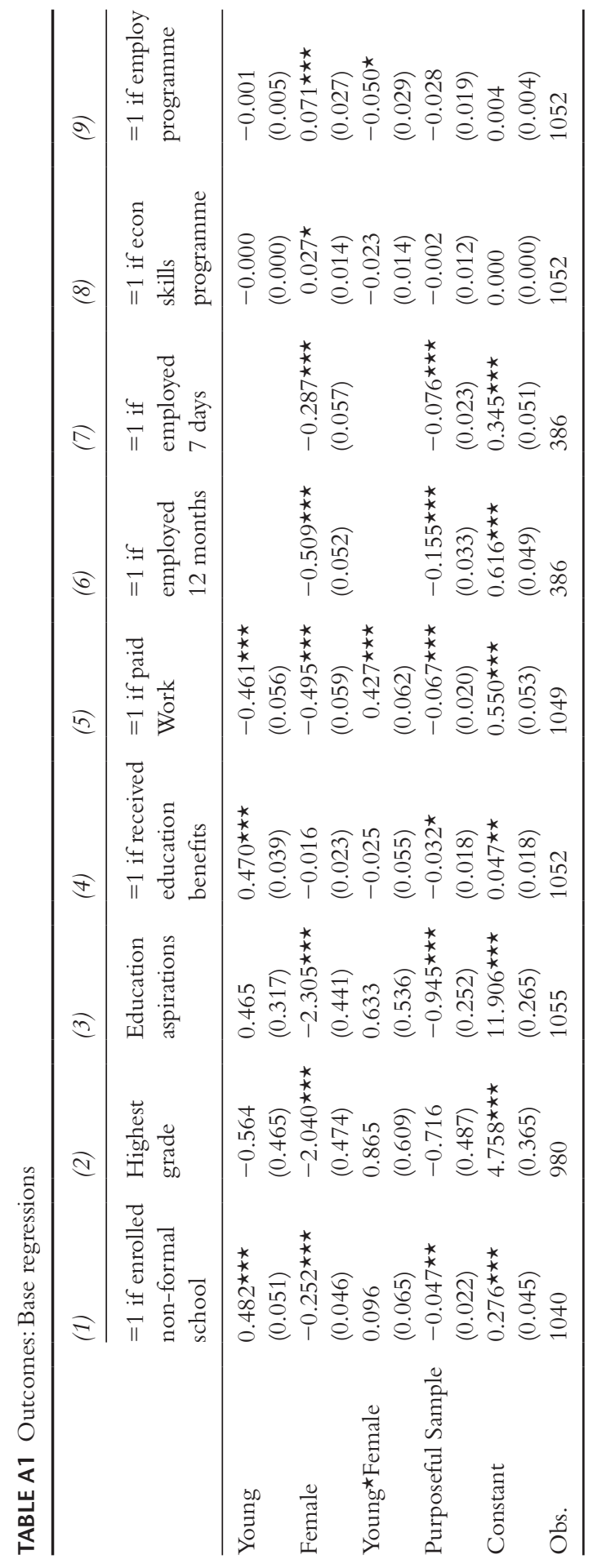

